\title{
MOLECULAR MARKERS FOR PARENTAGE ANALYSIS IN THE GROUPER F1 HYBRID EPINEPHELUS COIOIDES × EPINEPHELUS LANCEOLATUS (ACTINOPTERYGII: PERCIFORMES: SERRANIDAE)
}

\author{
Lee M. LIM ${ }^{1}$, Shigeharu SENOO ${ }^{2}$, Shafiquzzaman SIDDIQUEE ${ }^{1}$, \\ and Kenneth F. RODRIGUES ${ }^{1 *}$ \\ ${ }^{1}$ Biotechnology Research Institute, Universiti Malaysia Sabah, Kota Kinabalu, Sabah, Malaysia \\ ${ }^{2}$ Borneo Marine Research Institute, Universiti Malaysia Sabah, Kota Kinabalu, Sabah, Malaysia
}

Lim L.M., Senoo S., Siddiquee S., Rodrigues K.F. 2014. Molecular markers for parentage analysis in the grouper F1 hybrid Epinephelus coioides $\times$ Epinephelus lanceolatus (Actinopterygii: Perciformes: Serranidae). Acta Ichthyol. Piscat. 44 (1): 59-64.

Background. The aquaculture industry is driven by the need to develop novel interspecific hybrids with improved culture characteristics, however currently no molecular markers are available for the validation of F1 hybrids in the case of groupers. The presently reported study was directed toward the development of molecular markers for F1 hybrids obtained by artificial spawning of eggs derived from orange-spotted grouper, Epinephelus coioides (Hamilton, 1822), with sperm from giant grouper, E. lanceolatus (Bloch, 1790).

Materials and methods. DNA was extracted and purified from the fin clip of a single F1 hybrid of E. coioides $\times$ E. lanceolatus. Small insert shotgun genomics libraries were constructed, 40 positive transformants were sequenced, and the sequences deposited at the GenBank. Thirty locus-specific primer pairs were designed and tested across $64 \mathrm{~F} 1$ hybrid specimens as well as DNA samples extracted from coral grouper, Epinephelus corallicola (Valenciennes, 1828), and brown-marbled grouper, E. fuscoguttatus (Forsskål, 1775).

Results. A panel of thirty molecular markers was developed to verify parentage, of these eleven and six of the markers were inherited from the sire and dam respectively. Two markers were specific to the F1 hybrid and none of the markers could be assigned to the closely related groupers E. corallicola and E. fuscoguttatus.

Conclusion. The markers developed can be applied to assign parentage and determine the degree of introgression in interspecific grouper hybrids developed from E. coioides and E. lanceolatus. The methods developed in this study can be extended to characterize Quantitative Trait Loci (QTLs) and to identify interspecific F1 hybrids in the wild.

Keywords: Mendelian inheritance, heterosis, Dobzhansky-Muller incompatibility, single locus DNA markers, genomic library

\section{INTRODUCTION}

The aquaculture industry is increasingly turning towards the cultivation of interspecific grouper hybrids, which have been reported to exhibit higher growth rates and resistance to disease, characteristics which are likely to be the result of heterosis. Grouper hybrids have been documented in the case of goldblotch grouper, Epinephelus costae (Steindachner, 1878) $\times$ dusky grouper, E. marginatus (Lowe, 1834) (see Glamuzina et al. 2001); brown-marbled grouper, E. fuscoguttatus (Forsskål, 1775) $\times$ camouflage grouper, E. polyphekadion (Bleeker, 1849) (see James et al. 1999); as well as an F1 hybrid which has been developed from the giant grouper, E. lanceolatus (Bloch, 1790) and orange-spotted grouper, E. coioides (Hamilton, 1822) (see Kiriyakit et al. 2011).
Natural hybrids have been reported in leopard coralgrouper, Plectropomus leopardus (Lacepède, 1802) and spotted coralgrouper, P. maculatus (Bloch, 1790) (see van Herwerden et al. 2002) and in reef fishes of the family Serranidae (see Yaakub et al. 2006). Molecular markers are ideal for mapping inheritance patterns in fish (Liu and Cordes 2004) and have been developed and characterized for many species of groupers which include the humpback grouper, Cromileptes altivelis (Valenciennes, 1828) (see Na-Nakorn et al. 2010); the giant grouper, E. lanceolatus (see Yang et al. 2011); the Hawaiian grouper, Hyporthodus quernus (Seale, 1901) (see Rivera et al. 2003); and the brown-marbled grouper, E. fuscoguttatus (see Renshaw et al. 2012), however these molecular markers have been used in population genetic studies and not for inferring

* Correspondence: Dr. Kenneth Francis Rodrigues, Biotechnology Research Institute, Universiti Malaysia Sabah, 88400, Kota Kinabalu, Sabah, Malaysia, phone: +6088320000-5599, fax: +6088320993, e-mail: (KFR) kennethr@ums.edu.my, (LML)niclml@yahoo.com, (SS) ssenoo@ums.edu.my, (SSQ) shafiqpab@ums.ed.my. 
parentage and inheritance as was done in the case of tilapia hybrids developed from Oreochromis niloticus (Linnaeus, 1758) and Sarotherodon melanotheron Rüppell, 1852 (see Bezault et al. 2012). The current study was based on the F1 hybrid developed at the Borneo Marine Research Institute between an E. coioides (Female) and E. lanceolatus (Male) (Koh et al. 2010). The objective of this study, which was the determination of parentage, necessitated the development of single locus genomic molecular markers, which could then be applied to verify inheritance patterns. This was done using a bottom-up approach which involved the construction of a small insert genomic library for the F1 hybrid followed by mapping of the genomic loci against the parental genotypes.

\section{MATERIALS AND METHODS}

Sample collection and DNA extraction. Specimens of Epinephelus lanceolatus, E. fuscoguttatus, E. coioides, E. corallicola (Valenciennes, 1828) and F1 hybrids of E. coioides (Female) and E. lanceolatus (Male) are currently being maintained at the hatchery of the Borneo Marine Research Institute, Universiti Malaysia Sabah. Anal fin clips of approximately $1 \mathrm{~cm}^{2}$ were collected from each of the parental genotypes. An additional 64 samples were collected from one year-old F1 hybrid specimens. Ten samples were derived from E. corallicola and six from E. fuscoguttatus. DNA was extracted using the salting out protocol (Aljanabi and Martinez 1997) and the concentration of DNA was adjusted with sterile nuclease free water to $200 \mathrm{ng} \cdot \mu \mathrm{L}^{-1}$ and verified using a single drop spectrophotometer (GE Life Sciences).

Development of small insert genomic library. A small insert genomic library was constructed by digesting $200 \mathrm{ng}$ of genomic DNA from the F1 hybrid and $200 \mathrm{ng}$ of the circularized cloning vector pUC19 with the following combinations of restriction enzymes Bam HI/Hind III (5 Units each), Eco RI/Bam HI (5 Units each), Eco RI/Hind III (5 Units each), Xba I /Bam HI (5 Units each), and $X b a$ I/Hind III (5 Units each) in a reaction volume of $20 \mu \mathrm{L}$ comprising $2 \times$ Fermentas buffer Tango $(4.0 \mu \mathrm{L})$, restriction enzymes (5 Units), DNA (200 ng) and nuclease free water. Reaction mixtures were incubated at $37^{\circ} \mathrm{C}$ for $3 \mathrm{~h}$ followed by heating to $80^{\circ} \mathrm{C}$ for $20 \mathrm{~min}$ to inactivate the restriction enzymes. The DNA fragments were resolved on a $1 \times$ Tris-Boric acid-EDTA (TBE) agarose gel (Promega) followed by gel purification using a gel extraction kit according to the manufacturers instruction (Qiagen) and subsequently ligated onto the cloning vector pUC19 in a reaction mixture comprising $2 \times$ T4 DNA ligation buffer (Fermentas) $(2.0 \mu \mathrm{L})$, T4 DNA ligase (5 Units), genomic DNA fragments (100 ng), linearized pUC19 cloning vector (200 $\mathrm{ng}$ ), and nuclease free water to a final volume of $20 \mu \mathrm{L}$. Ligation was carried out at $4^{\circ} \mathrm{C}$ for $16 \mathrm{~h}$. The ligation mixture was transformed into chemically competent Escherichia coli (TOP 10) by immersion in a water bath set at $37^{\circ} \mathrm{C}$ for $40 \mathrm{~s}$ followed by plating of $100 \mu \mathrm{L}$ of the transformed cells onto lysogeny agar containing $100 \mu \mathrm{g} \cdot \mathrm{mL}^{-1}$ of ampicillin and $5 \mu \mathrm{g} \cdot \mathrm{mL}^{-1}$ of X-Gal fol- lowed by incubation for $16 \mathrm{~h}$ at $42^{\circ} \mathrm{C}$. Positive transformants were selected by blue-white colony screening and single colonies were cultured in $10 \mathrm{~mL}$ of lysogeny broth containing ampicillin $\left(100 \mu \mathrm{g} \cdot \mathrm{mL}^{-1}\right)$. Plasmids were extracted using the GenJET plasmid minipreparation kit (Fermentas) followed by sequencing using the BigDye Terminator v3.1 cycle sequencing kit (Applied Biosystems). Sequences were trimmed using the Vec Screen software (NCBI) and 40 of the edited sequences were deposited at the NCBI GenBank. Sequence similarity was determined using the blast tool (Zhang et al. 2000) and sequences with a coverage in excess of $50 \%$ were deemed to be significant matches to the fish genome database.

Design of locus specific primers and testing in parental genotypes, F1 hybrids and related groupers. Locus specific primers were designed for each of the 40 loci using the online primer design tool Primer 3.0 (Rozen and Skaletsky 1999) and 30 primer pairs were synthesized (First Base, Singapore). Primers were reconstituted in nuclease free water to a final concentration of $100 \mu \mathrm{M}$. PCR amplification was performed in final volume of $20 \mu \mathrm{L}$ which consisted of $1.2 \mu \mathrm{L} \mathrm{MgCl}_{2}(1.5 \mathrm{mM}), 0.4 \mu \mathrm{L}$ dNTPs $(0.2 \mathrm{mM}), 4 \mu \mathrm{L} 1 \times$ GoTaq buffer (Promega, USA), 1 U Taq DNA polymerase (Fermentas, USA), $1 \mu \mathrm{L}$ of each primer $(5 \mu \mathrm{M}), 3 \mu \mathrm{L}$ template and nuclease free water. Amplification was performed in the thermal cycler (MJ research, PTC-200) with the parameters of the cycler pre-denaturation at $95^{\circ} \mathrm{C}$ for $3 \mathrm{~min}$, this was followed by 30 cycles of denaturation $\left(30 \mathrm{~s}\right.$ at $\left.95^{\circ} \mathrm{C}\right)$, annealing $(40 \mathrm{~s}$ at $\left.56^{\circ} \mathrm{C}\right)$, extension $\left(2 \mathrm{~min}\right.$ at $\left.72^{\circ} \mathrm{C}\right)$ and final extension $\left(10 \mathrm{~min}\right.$ at $\left.72^{\circ} \mathrm{C}\right)$. PCR products were resolved by gel electrophoresis on a $1.5 \%$ TBE Agarose gel (Promega) followed by staining for $10 \mathrm{~min}$ in a solution of ethidium bromide $\left(5 \mu \mathrm{g} \cdot \mathrm{mL}^{-1}\right)$. Gels were then rinsed by immersion in water for $5 \mathrm{~min}$ and visualized and scored using a gel documentation system ALPHAIMAGER 2000 (Alpha Innotech Corp. USA).

Ethical issues. The samples were isolated from specimens which are currently being maintained at the Borneo Marine Research Institute, Universiti Malaysia Sabah, in compliance to the institutional Animal Care and Use Committee (ACUC) guidelines.

\section{RESULTS}

Sample collection and DNA extraction. The sample collection and DNA extraction protocols yielded DNA, which was of the required quality $\left(\mathrm{A}_{260}: \mathrm{A}_{280}=1.8-2.0\right)$ and concentration $\left(100-300 \mu \mathrm{g} \cdot \mathrm{mL}^{-1}\right)$ for genomic library construction and polymerase chain reaction.

Development of small insert genomic library. A total of 40 genomic loci were deposited at the NCBI GenBank (Accession numbers JQ732815-JQ732778). Sequence similarity searches revealed that the following eight accessions could be mapped back to fish genomes with sequence coverage in excess of 50\%: JQ732778 [Danio rerio (Hamilton, 1822)], JQ732785 (E. lanceolatus), JQ732786 (E. fuscoguttatus), JQ732785 (E. lanceolatus $\times$ E. fuscoguttatus), JQ732794 [Perca flavescens (Mitchill, 
1814)], JQ732795 (E. fuscoguttatus), JQ732798 [E. fuscoguttatus; Dicentrarchus labrax (Linnaeus, 1758); Gasterosteus aculeatus Linnaeus, 1758], JQ732814 (Oreochromis niloticus), JQ732809 (E. coioides $\times$ E. fuscoguttatus), and JQ732815 (Cromileptes altivelis). The remaining 32 accessions could be mapped back to the fish genome database, however the level of coverage was less than $50 \%$ and these matches were considered not significant. Design and application of locus specific genomic molecular markers. A panel of 30 locus specific molecular markers were designed, of which 29 generated PCR amplicons of the expected size, one of the primer pairs (ECELEB008) failed to amplify in the F1 hybrid or the parents, 13 loci were found to be common to both the parents, 11 and 6 were inherited from E. lanceolatus and E. coioides, respectively (Fig. 1). Two of the loci, ECELEH007 and ECELEB001 were specific to the F1 hybrid and not associated with the parents. Three of the primers ECELBH003, ECELB013 and ECELXB003 produced two distinct bands in the $\mathrm{F} 1$ hybrid and one in each of the parental genotypes which were designated as A, B, and AB (Table 1). None of the molecular markers could cross-amplify in the closely related groupers E. fuscoguttatus and E. corallicola. Primer amplification was uniform across the entire set of samples which were tested.

\section{DISCUSSION}

Genomic library development. Small insert genomic libraries constructed using a shotgun approach provide a widely dispersed set of genomic DNA fragments which can be sequenced in order to develop single locus molecular markers. The current approach utilized five combinations of restriction enzymes in order to reduce the level of redundancy in genomic coverage. The sequences, which had a significant level of similarity to fish genomes represented non-coding regions of DNA and can be considered as Type II molecular markers.

Design and application of locus specific genomic molecular markers. The commercial aquaculture industry has directed a significant amount of effort towards the development of grouper hybrids as it is generally assumed that there will be an increase in the levels of allelic diversity and the associated development of characteristics which are desired in aquaculture systems. One of the major driver of this effort has been the increase in the incidence of disease and the need to develop resistant varieties (Harikrishnan et al. 2010). In conventional breeding approaches involving interspecific grouper hybrids, the selection of the parental genotypes is based purely on phenotypic characterization, for instance an F1 hybrid was developed from $E$. fuscoguttatus $\times$ E. polyphekadion (see James et al. 1999) solely on the basis of the higher growth rate of the hybrid when compared to the dam and sire. Contemporary approaches using molecular markers extend the scope of selection beyond the phenotype and provide a more accurate indicator of genetic compatibility and hybrid viability. Three key criteria have to be considered when selecting parental genotypes for hybridiza- tion; the first relates to the genetic distance between species, the second concerns interspecific genetic viability which is governed by the Dobzhansky-Muller Incompatibility (DMI) model and the third pertains to variations in the number of chromosomes, which can result in complications in chromosomal rearrangements after the formation of the zygote. The first criterion, which relates to genetic distance, can be resolved using molecular phylogenetics. A reconstruction of grouper phylogenetic trees using molecular data (Craig and Hastings 2007) clearly delineates the relation between groupers and E. coioides and E. lanceolatus clustered together in one clade with a high level of confidence. This is supported by the fact that 13 of the 29 markers tested were shared between both $E$. coioides and E. lanceolatus indicating a high level of genomic similarity at randomly selected loci.

The second criterion which concerns DMI needs to be further examined in view of the evidence that indicates a lower percentage of survival among hybrids (Kiriyakit et al. 2011), this phenomenon has also been reported in hybrids developed in Sunfish (López-Fernández and Bolnick 2007) and has been attributed to incomplete penetrance. Similar evidence for attenuation of hybrid vigor has been reported in a study involving Flounder hybrids (Xu et al. 2011) and these findings must be carefully considered prior to hybrid breeding programs involving groupers. The markers developed for this study amplified consistently in all of the F1 samples tested, these represent the individuals which have survived for a period of one year after hatching and may be indicative of the alleles which confer fitness in the case of this particular hybrid. One of the major ecological concerns associated with F1 hybrids is the possibility of their escape from containment followed by inbreeding with native populations (Allendorf et al. 2001). Two of the molecular markers developed were specific to the F1 hybrid and these can be applied for the analysis of individuals from wild grouper populations in order to detect any possible breach of containment at the aquaculture facility.

The third criterion is the uniformity in the number of chromosomes. Karyotype analysis (Wang et al. 2009) of groupers indicates a consistency in the number of chromosomes $(2 n=48)$ within the genus Epinephelus further supporting the premise that interspecific grouper hybrids will be viable (Stelkens et al. 2009). The application of Haldane's rule in the case of protogynous hermaphrodites is further complicated as there was no evidence of sexual dimorphism in the F1 hybrids and sex reversal can take several years (Yeh et al. 2003).

None of the markers developed in this study could be assigned to the groupers E. corallicola and E. fuscoguttatus, this may provide a strong molecular basis for not selecting these two species for hybridization with E. coioiodes or E. lanceolatus owing to the genetic distance as evinced using multiple genomic loci. The study clearly indicated that molecular markers developed using the bottom up approach could serve as a useful tool in 
determining parentage in $\mathrm{F} 1$ hybrids developed from groupers.

\section{CONCLUSIONS}

This study was carried out to verify parentage in F1 hybrids developed from E. coioides and E. lanceolatus.
A small insert genomic library was constructed based on the F1 hybrid and single locus molecular markers could be assigned to each of the parental genotypes and not to two other closely related species of grouper. The approach adopted in this study can be applied to develop breeding programs for interspecific hybrids based on molecular markers.
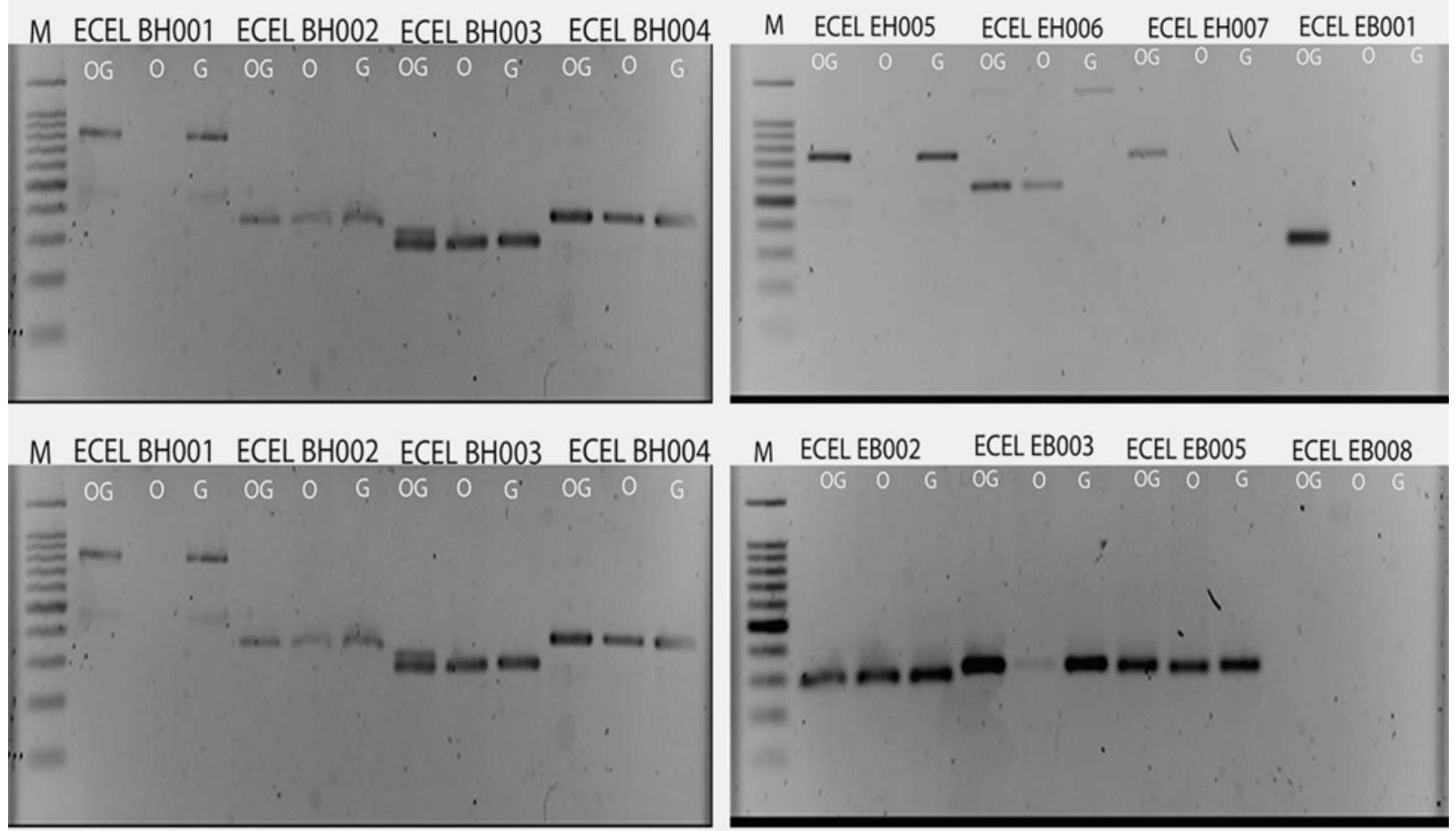

M ECEL BH010 ECEL BH011 ECEL BH012 ECEL BH013
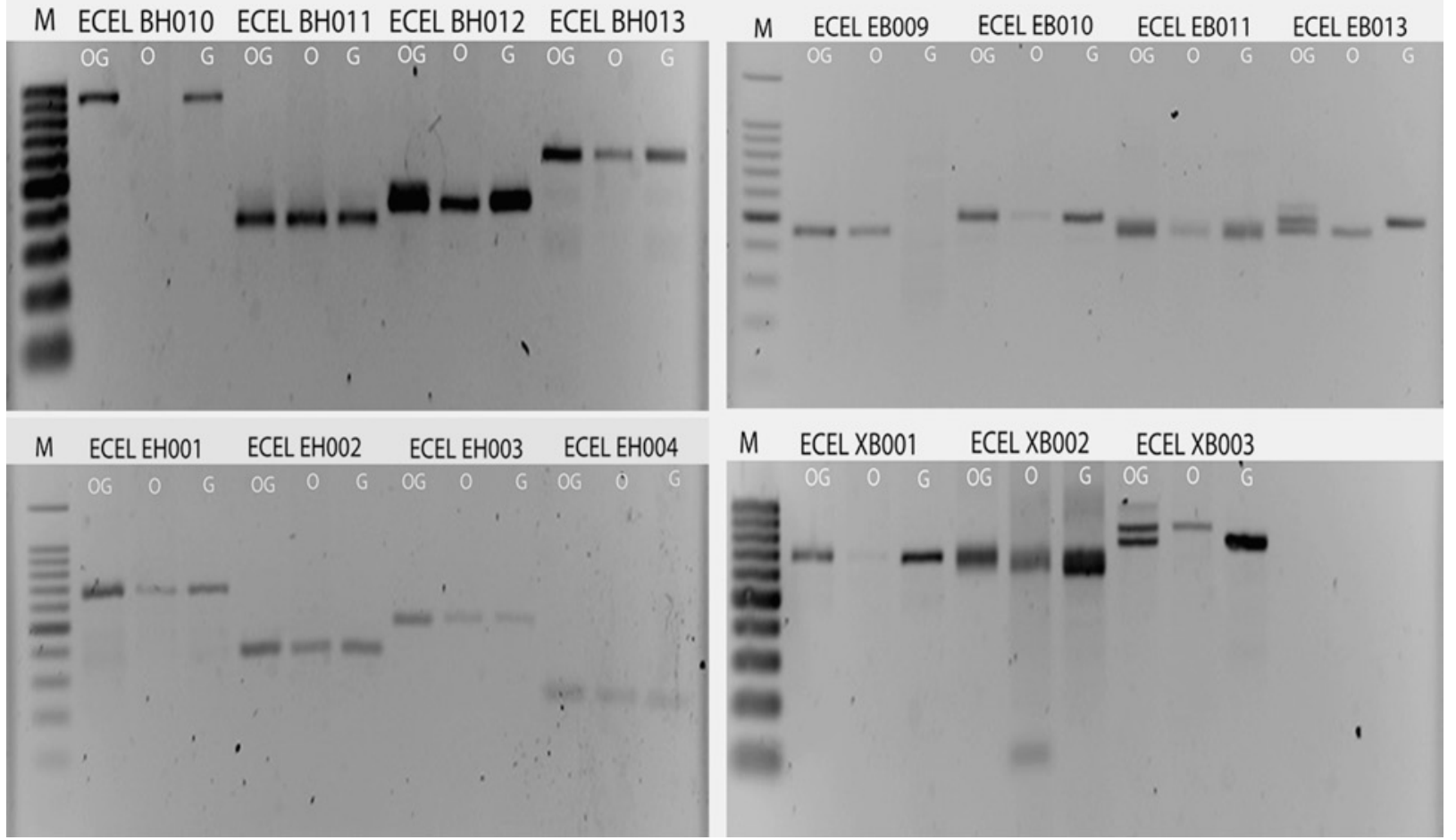

Fig. 1. Gel image of cross amplification comparing the FI grouper hybrid of Epinephelus coioides and Epinephelus lanceolatus against parental species that are Epinephelus coioides and Epinephelus lanceolatus; Lane M represents the $100 \mathrm{bp}$ DNA ladder (Promega); lanes OG represent the amplification products of FI grouper hybrid of Epinephelus coioides and Epinephelus lanceolatus; Lanes O represents the amplification products of Epinephelus coioides and lanes $\mathrm{G}$ represents the amplification products of Epinephelus lanceolatus for the labelled genomic locus respectively 
Table 1

Polymerase Chain Reaction (PCR) amplification profiles of locus specific molecular markers developed for the F1 hybrid of Epinephelus coioides and E. lanceolatus

\begin{tabular}{|c|c|c|c|c|c|c|c|c|}
\hline No. & Primer name & Sequence from $5^{\prime}$ through $3^{\prime}$ & $\mathrm{Tm}$ & $\begin{array}{c}\text { Product size } \\
{[\mathrm{bp}]}\end{array}$ & F1 & EC & EL & GenBank \\
\hline \multirow{2}{*}{1} & ECELBH001F & CAGATGCCTGACAACCTCAA & 59.83 & \multirow{2}{*}{814} & \multirow[t]{2}{*}{+} & \multirow[t]{2}{*}{-} & \multirow{2}{*}{+} & \multirow{2}{*}{ JQ732777 } \\
\hline & ECELBH001R & АCTCTCCTTGCCTCTGACCA & 59.99 & & & & & \\
\hline \multirow{2}{*}{2} & ECELBH002F & TAGCCTCATGCCCTCCTAGA & 59.93 & \multirow{2}{*}{367} & \multirow[t]{2}{*}{+} & \multirow{2}{*}{+} & \multirow{2}{*}{+} & \multirow{2}{*}{ JQ732778 } \\
\hline & ECELBH002R & GTGCCATACGGCTTTGAAAT & 59.97 & & & & & \\
\hline \multirow{2}{*}{3} & ECELBH003F & CCTGTCAGTGGCAACAACAA & 60.76 & \multirow{2}{*}{311} & $\mathrm{AB}$ & B & A & \\
\hline & ECELBH003R & GGATGGCCTGAAAATACACG & 60.33 & & & & & $J Q / 327 / 9$ \\
\hline 4 & ECELBH004F & GATGAACCAAACACCCCAAC & 60.07 & 399 & + & + & + & JO732780 \\
\hline 4 & ECELBH004R & TCGCCACAATCTCTGAACTG & 59.98 & 399 & & & & JQ/32/80 \\
\hline 5 & ECELBH005F & CACCACAACAGAATGGCAAC & 60.01 & 712 & + & - & + & \\
\hline 3 & ECELBH005R & AAACGATCTCTCGCCAAGAA & 59.96 & 112 & & & & \\
\hline & ECELBH006F & GAAGACGGGGTGACATGTTT & 59.83 & & + & + & - & \\
\hline 0 & ECELBH006R & GGTGGGCATTCTTCTTTGTG & 60.50 & $3 / 4$ & & & & JQ/32/82 \\
\hline 7 & ECELBH008F & CCTGTTCCCACTGTGACTGA & 59.70 & 761 & + & - & + & JO732784 \\
\hline 1 & ECELBH008R & TGACCTCTTCCATTCCCTTG & 60.04 & 101 & & & & JQ/32/84 \\
\hline 8 & ECELBH010F & ACGTGGCTTCGAGGAGTAAA & 59.88 & 958 & + & - & + & J0732786 \\
\hline 0 & ECELBH010R & AGAACGACCAGCCTCTTTGA & 59.99 & (500 & & & & ग्राइ2100 \\
\hline 9 & ECELBH011F & TCGCGTAACCTCTCTGTCCT & 60.01 & 383 & + & + & + & \\
\hline S & ECELBH011R & CCTGTGTGGAAACCAAAGGT & 59.86 & 503 & & & & \\
\hline 10 & ECELBH012F & GCCTTTTGTTGAGGGAACTG & 59.71 & 438 & + & + & + & \\
\hline 10 & ECELBH012R & СССАСССТСАТТСТСТTТСА & 60.04 & 458 & & & & गQ/32/88 \\
\hline 11 & ECELBH013F & GGGAAAGAGAAGGTGGAAGG & 60.04 & 611 & + & + & + & JQ732789 \\
\hline 11 & ECELBH013R & CGTTAGTGCATCCCCTTGAT & 59.96 & 011 & & & & JQ/32/09 \\
\hline 12 & ECELEB001F & TCAGGAAAGCGTTGGAGAGT & 59.99 & 367 & + & - & - & JO732790 \\
\hline 12 & ECELEB001R & CAGGGGTAAAGGCACTTCAG & 59.73 & & & & & 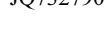 \\
\hline 13 & ECELEB002F & GGCAGAGAGAGAGCGAGATG & 60.39 & 290 & + & + & + & JO7327 \\
\hline 10 & ECELEB002R & GCTATGCAGCTACAGGCAGA & 59.35 & 290 & & & & गQ/32/91 \\
\hline 14 & ECELEB003F & CATGGCGAGTAGGACACAGA & 59.86 & 323 & + & - & + & \\
\hline 14 & ECELEB003R & CACCTCGGCTCTAAACTTCG & 60.01 & 325 & & & & \\
\hline 15 & ECELEB005F & TCCGTTACTTCCCACCAGAC & 59.97 & 312 & + & + & + & JO732793 \\
\hline 13 & ECELEB005R & CGACAGGAACAGCTGATGAA & 59.98 & 312 & & & & JQ/32/93 \\
\hline 16 & ECELEB008F & GTGCCTGACAACGCTAGAAG & 59.68 & 674 & - & - & - & JO732795 \\
\hline 10 & ECELEB008R & CCAGGGAAACCAGCTTATGA & 60.07 & & & & & \\
\hline 17 & ECELEB009F & AAATGTGTGTGGGTGGGTTT & 59.99 & 453 & + & + & - & JO732796 \\
\hline 11 & ECELEB009R & ATGACGTGAATCCATCAGCA & 60.08 & 430 & & & & \\
\hline 18 & ECELEB010F & СТTTCССТTТСССТСАССТC & 60.04 & 50 & + & - & + & \\
\hline 10 & ECELEB010R & CTGTCGTCAGGCATCTCTCA & 60.14 & 503 & & & & JQ/32, \\
\hline 19 & ECELEB011F & GATTACACGCCACTCAGCAA & 59.87 & 451 & + & + & + & \\
\hline 19 & ECELEB011R & TGAAAAGAAACCTGGGGTTG & 59.94 & 451 & & & & JQ/32/90 \\
\hline 20 & ECELEB013F & CGATCCCAACCAGAGTCATT & 59.93 & 506 & $\mathrm{AB}$ & B & A & JO732800 \\
\hline & ECELEB013R & GGTTTGTCCATTCTGGGCTA & 59.93 & & & & & \\
\hline 21 & ECELEH001F & GATGTCGTGTTGGACTGTGG & 60.00 & 658 & + & + & + & JO732801 \\
\hline & ECELEH001R & CTTCCAGCCTACCTTTGCAC & 59.88 & & & & & \\
\hline 22 & ECELEH002F & AATCTGACACCCTGGAGCTG & 60.26 & 38 & + & + & + & \\
\hline 22 & ECELEH002R & ACGGGACTCAACCAAACATC & 59.83 & SoJ & & & & ग्राउ \\
\hline 23 & ECELEH003F & GCGACACAGGTCAAGTCTCA & 60.03 & 506 & + & + & + & JO732803 \\
\hline 23 & ECELEH003R & GCGATAGATCCCATCCTGAA & 60.00 & & & & & ग्रागयण \\
\hline 24 & ECELEHOO4F & ACTCAACTAGCAGCCCAGGA & 60.01 & 234 & + & + & + & JO732804 \\
\hline & ECELEH004R & TGAGGACATTTGGGGCTTAG & 60.07 & & & & & \\
\hline 25 & ECELEH005F & AGTCACTGCCGCTGAAAGAT & 60.02 & 752 & + & - & + & J0732805 \\
\hline 25 & ECELEH005R & CCACAGGTAGAAGGCATGGT & 59.99 & 152 & & & & JQ/32805 \\
\hline 26 & ECELEH006F & CTAATCCTGGCTGGCATGTT & 60.10 & 562 & + & + & - & \\
\hline 20 & ECELEH006R & CCACGATGACCCAGAAGAAT & 59.93 & 502 & & & & JQ/ 132000 \\
\hline 27 & ECELEH007F & AACACACCAGAAGGGTCTGC & 60.16 & 733 & + & - & - & JQ732807 \\
\hline & ECELEH007R & TTTTTGGGGTGGCAGTAGTC & 59.97 & & & & & JQ/3280/ \\
\hline 28 & ECELXB001F & CCCTCTGGGGTAGATTGTGA & 59.92 & 715 & + & - & + & JQ732808 \\
\hline & ECELXB001R & TATGTGGCGTGTCAGAGGAG & 59.86 & 115 & & & & \\
\hline 29 & ECELXB002F & GACTAATGATGGCAGCAGCA & 59.98 & 621 & + & + & + & 2809 \\
\hline 29 & ECELXB002R & CTGGCTCCCTGTAAAATCCA & 60.07 & 021 & & & & JQ/32809 \\
\hline 30 & ECELXB003F & ATGTGCGTCTTCGAGAGGTT & 59.87 & 763 & $\mathrm{AB}$ & A & B & 32810 \\
\hline 50 & ECELXB003R & CACTGCAGCGCTAATAACCA & 60.04 & & & & & 702010 \\
\hline
\end{tabular}

No. $=$ number, $\mathrm{Tm}=$ annealing temperature, $\mathrm{F} 1=\mathrm{F} 1$ hybrid, $\mathrm{EC}=$ Epinephelus coioides, $\mathrm{EL}=$ Epinephelus lanceolatus, GenBank $=$ GenBank accession numbers for loci; positive amplification (+), no amplification (-), alleles are indicated by A, $\mathrm{B}$, and $\mathrm{AB}$. 


\section{ACKNOWLEDGEMENTS}

This study was funded by the Ministry of Agriculture, Government of Malaysia grant number: SCF05-01-10-SF1010.

\section{REFERENCES}

Aljanabi S.M., Martinez I. 1997. Universal and rapid saltextraction of high quality genomic DNA for PCR-based techniques. Nucleic Acids Research 25 (22): 4692-4693. DOI: $10.1093 /$ nar/25.22.4692

Allendorf F.W., Leary R.F., Spruell P., Wenburg J.K. 2001. The problems with hybrids: setting conservation guidelines. Trends in Ecology and Evolution 16 (11): 613-622. DOI: 10.1016/S0169-5347(01)02290-X

Bezault E., Rognon X., Clota F., Gharbi K., Baroiller J.-F., Chevassus B. 2012. Analysis of the meiotic segregation in intergeneric hybrids of Tilapias. International Journal of Evolutionary Biology 2012: 10 pages. DOI: 10.1155/2012/817562

Craig M.T., Hastings P.A. 2007. A molecular phylogeny of the groupers of the subfamily Epinephelinae (Serranidae) with a revised classification of the Epinephelini (1983). Ichthyological Research 54 (1): 1-17. DOI: 10.1007/ s10228-006-0367-x

Glamuzina B., Glavić N., Skaramuca B., Kozul V., Tutman P. 2001. Early development of the hybrid Epinephelus costae o $\times$ E. marginatus $\hat{\jmath}$. Aquaculture 198 (1-2): 55-61. DOI: 10.1016/S0044-8486(00)00511-1

Harikrishnan R., Balasundaram C., Heo M.-S. 2010. Molecular studies, disease status and prophylactic measures in grouper aquaculture: Economic importance, diseases and immunology. Aquaculture 309 (1-4): 1-14. DOI: 10.1016/j.aquaculture.2010.09.011

James C.M., Al-Thobaiti S.A., Rasem B.M., Carlos M.H. 1999. Potential of grouper hybrid (Epinephelus fuscoguttatus $\times$ E. polyphekadion) for Aquaculture. Naga, the ICLARM Quarterly 22 (1): 19-23.

Kiriyakit A., Gallardo W.G., Bart A.N. 2011. Successful hybridization of groupers (Epinephelus coioides $\times$ Epinephelus lanceolatus) using cryopreserved sperm. Aquaculture 320 (1-2): 106-112. DOI: 10.1016/j.aquaculture.2011.05.012

Koh I.C.C., Sitti Raehanah M.S., Akazawa N., Ota Y., Senoo S. 2010. Egg and larval development of a new hybrid orangespotted grouper Epinephelus coioides $\times$ giant grouper $E$. lanceolatus. Aquaculture Science 58 (1): 1 -10. DOI: 10.11233/aquaculturesci.58.1

Liu Z.J., Cordes J.F. 2004. DNA marker technologies and their applications in aquaculture genetics. Aquaculture 238 (1-4): 1-37. DOI: 10.1016/j.aquaculture.2004.05.027

López-Fernández H., Bolnick D.I. 2007. What causes partial F1 hybrid viability? Incomplete penetrance versus genetic variation. PLoS ONE 2 (12): e1294. DOI: 10.1371/journal.pone.0001294

Na-Nakorn U., Yashiro R., Wachirachaikarn A., Prakoon W., Pansaen N. 2010. Novel microsatellites for multiplex PCRs in the humpback grouper, Cromileptes altivelis (Valenciennes, 1828), and applications for broodstock management. Aquaculture 306 (1-4): 57-62. DOI: 10.1016/ j.aquaculture.2010.05.022
Renshaw M.A., Nemeth R.S., Gold J.R. 2012. Isolation of microsatellite markers from tiger grouper (Mycteroperca tigris) and characterization in yellowfin grouper (Mycteroperca venenosa), coney (Cephalopholis fulva), and red hind (Epinephelus guttatus). Conservation Genetics Resources 4 (4): 1049-1054. DOI: 10.1007/s12686-012-9704-8

Rivera M.A.J., Graham G.C., Roderick G.K. 2003. Isolation and characterization of nine microsatellite loci from the Hawaiian grouper Epinephelus quernus (Serranidae) for population genetic analyses. Marine Biotechnology 5 (2): 126-129. DOI: 10.1007/s10126-002-0093-y

Rozen S., Skaletsky H. 1999. Primer3 on the WWW for general users and for biologist programmers. Pp. 365-386. In: Misener S., Krawetz S.A. (eds.) Bioinformatics methods and protocols. Vol. 132 of Methods in Molecular Biology Humana. Press, Totowa, NJ, USA. DOI: 10.1385/1-59259-192-2:365

Stelkens R.B., Schmid C., Selz O., Seehausen O. 2009. Phenotypic novelty in experimental hybrids is predicted by the genetic distance between species of cichlid fish. BMC Evolutionary Biology 9 (December) paper 283: 13 pages. DOI: 10.1186/1471-2148-9-283

van Herwerden L., Davies C.R., Choat J.H. 2002. Phylogenetic and evolutionary perspectives of the IndoPacific grouper Plectropomus species on the Great Barrier Reef, Australia. Journal of Fish Biology 60 (6): 1591-1596. DOI: 10.1111/j.1095-8649.2002.tb02451.x

Wang S., Su Y., Ding S., Cai Y., Wang J. 2009. Cytogenetic analysis of orange-spotted grouper, Epinephelus coioides, using chromosome banding and fluorescence in situ hybridization. Hydrobiologia 638 (1): 1-10. DOI: 10.1007/s10750-009-9980-9

Xu D., You F., Li J., Wu Z., Xiao Z., Zhang P., Xu Y., Wang B. 2011. First evidence for hybrid breakdown in the backcross of olive flounder, Paralichthys olivaceus, and summer flounder, Paralichthys dentatus. Journal of the World Aquaculture Society 42 (3): 347-353. DOI: 10.1111/j.17497345.2011.00473.x

Yaakub S.M., Bellwood D.R., van Herwerden L., Walsh F.M. 2006. Hybridization in coral reef fishes: Introgression and bi-directional gene exchange in Thalassoma (family Labridae). Molecular Phylogenetics and Evolution 40 (1): 84-100. DOI: 10.1016/j.ympev.2006.02.012

Yang S., Wang L., Zhang Y., Liu X.C., Lin H.R., Meng Z.N. 2011. Development and characterization of 32 microsatellite loci in the giant grouper Epinephelus lanceolatus (Serranidae). Genetics and Molecular Research 10 (4): 4006-4011. DOI: 10.4238/2011.December.12.3

Yeh S.-L., Dai Q.-C., Chu Y.-T., Kuo C.-M., Ting Y.-Y., Chang C.-F. 2003. Induced sex change, spawning and larviculture of potato grouper, Epinephelus tukula. Aquaculture 228 (1-4): 371-381. DOI: 10.1016/S0044-8486(03)00316-8

Zhang Z., Schwartz S., Wagner L., Miller W. 2000. A greedy algorithm for aligning DNA sequences. Journal of Computational Biology 7 (1-2): 203-214. DOI: 10.1089/ 10665270050081478

Received: 6 May 2013

Accepted: 6 February 2014

Published electronically: 31 March 2014 